\title{
THE PLASMA MEMBRANE OF RAM, BOAR AND BULL SPERMATOZOA
}

\author{
R. G. JONES* \\ Wellcome Institute of Comparative Physiology, The Zoological Society of London, \\ Regent's Park, London $\mathcal{N W} 14 R$ Y
}

(Received 27th November 1972)

Spermatozoa of domestic animals may vary considerably in response to handling in the laboratory (Mann, 1964) and during preparation for artificial insemination (Jones, 1971a), but it is not known why such structurally similar cells should behave so differently. The plasma membranes of spermatozoa from the various species may differ in physical properties, but because spermatozoa are structurally unsuitable for tests which are performed on other cells, such as erythrocytes, this is not an easy hypothesis to test.

Jones (1971b) found that when boar semen was fixed in solutions of glutaraldehyde containing from $175 \mathrm{~mm}$ - to $100 \mathrm{~mm}$-sodium cacodylate, the decrease in buffer concentration caused the plasma membranes of the spermatozoa to swell and break; around the head, where the response was greatest, the amount of swelling and incidence of breakage was inversely related to the buffer concentration of the fixative. As these methods may provide a measure for comparing the properties of the plasma membrane of spermatozoa, the following studies were carried out to compare the response to fixation of ram, boar and bull spermatozoa.

Two ram ejaculates were collected following electrical stimulation (Nichols \& Edgar, 1964) whilst eight other ejaculates from the ram, nine from the boar (the sperm-rich fraction was collected separately for use) and nine from the bull were collected using an artificial vagina. Only samples containing a high proportion of spermatozoa with good activity were used. Jones (1971b) has described the methods of fixation and preparation of spermatozoa for examination with the transmission electron microscope, recording of electron micrographs (magnification $\times 5000$ ) from different areas of an Araldite section of each treatment and examination of prints (print magnification $\times 2$ ). Prints were examined and spermatozoa sectioned through the acrosome were scored according to whether the plasma membrane was intact or broken, with acrosome contents of homogeneous electron density ('normal'), or whether the plasma membrane was broken and the acrosome vacuolated or lost from the spermatozoon. Counts of the frequency of each type of score were expressed as mean percentages together with the average number of scores (i.e. spermatozoa) per treatment for each ejaculate $(n)$. Percentages were transformed to angles for

* Present address: Department of Biological Sciences, University of Newcastle, N.S.W. 2308, Australia. 
the analyses of variance in which orthogonal polynomial coefficients were used to test treatment main effects.

For each species, the experiment was a $4 \times 4$ randomized block design: $1 \%$ glutaraldehyde was used in $100,125,150$ or 175 mm-sodium cacodylate (osmolalities of buffer solutions were 200, 250, 300 and $350 \mathrm{mosmol} / \mathrm{kg}$ respectively, $\mathrm{pH} 7 \cdot 3$; Jones, 1971a), and the treatments were replicated with ejaculates from four different males. In addition, samples from five or six other animals of each species were fixed in glutaraldehyde in 150 mm-sodium cacodylate $(\mathrm{pH} \mathrm{7 \cdot 3).}$

No effect of fixation was observed in sub-samples of spermatozoa examined with the light microscope. Qualitatively, the effects on the sperm ultrastructure of varying the buffer concentration of the fixatives was very similar for the ram

Table 1. Effect of concentration of sodium cacodylate in fixatives on the incidence of breakage of the plasma membrane covering the acrosomes of ram, boar and bull spermatozoa

\begin{tabular}{|c|c|c|c|}
\hline & $\begin{array}{l}\text { Mean pe } \\
\text { p.m. intact } \\
\quad \text { and } \\
\text { acr. normal }\end{array}$ & $\begin{array}{l}\text { ges of spermo } \\
\text { p.m. broken } \\
\quad \text { and } \\
\text { acr. normal }\end{array}$ & $\begin{array}{l}\text { zoa with: } \\
\text { p.m. broken* } \\
\text { and } \\
\text { acr. vacuolated } \dagger\end{array}$ \\
\hline $\begin{array}{l}\text { Ram semen }(n=87 \cdot 8) \\
100 \text { mM-sodium cacodylate } \\
125 \text { mM-sodium cacodylate } \\
150 \text { mM-sodium cacodylate } \\
175 \text { mM-sodium cacodylate }\end{array}$ & $\begin{array}{l}56 \cdot 5 \\
53 \cdot 0 \\
63 \cdot 3 \\
84 \cdot 0\end{array}$ & $\begin{array}{l}40 \cdot 0 \\
44 \cdot 0 \\
34 \cdot 3 \\
14 \cdot 8\end{array}$ & $\begin{array}{l}3 \cdot 5 \\
3 \cdot 0 \\
2 \cdot 5 \\
1 \cdot 3\end{array}$ \\
\hline $\begin{array}{l}\text { Boar semen }(n=82 \cdot 5) \\
100 \mathrm{~mm} \text {-sodium cacodylate } \\
125 \mathrm{~mm} \text {-sodium cacodylate } \\
150 \mathrm{~mm} \text {-sodium cacodylate } \\
175 \mathrm{~mm} \text {-sodium cacodylate }\end{array}$ & $\begin{array}{l}44 \cdot 0 \\
64 \cdot 5 \\
73 \cdot 0 \\
84 \cdot 8\end{array}$ & $\begin{array}{l}51 \cdot 8 \\
32 \cdot 0 \\
21 \cdot 5 \\
10 \cdot 3\end{array}$ & $\begin{array}{l}4 \cdot 3 \\
3 \cdot 5 \\
5 \cdot 5 \\
5 \cdot 0\end{array}$ \\
\hline $\begin{array}{l}\text { Bull semen }(n=95 \cdot 8) \\
100 \mathrm{~mm} \text {-sodium cacodylate } \\
125 \mathrm{~mm} \text {-sodium cacodylate } \\
150 \mathrm{~mm} \text {-sodium cacodylate } \\
175 \mathrm{~mm} \text {-sodium cacodylate }\end{array}$ & $\begin{array}{l}90 \cdot 0 \\
91 \cdot 5 \\
94 \cdot 5 \\
93 \cdot 8\end{array}$ & $\begin{array}{l}7 \cdot 2 \\
6 \cdot 0 \\
2 \cdot 3 \\
2 \cdot 5\end{array}$ & $\begin{array}{l}2 \cdot 8 \\
2 \cdot 5 \\
3 \cdot 3 \\
3 \cdot 8\end{array}$ \\
\hline
\end{tabular}

p.m. = plasma membrane; acr. = acrosome.

* The plasma membrane was absent over the acrosome of most spermatozoa.

$\dagger$ Includes spermatozoa showing varying degrees of vacuolation of the acrosome, but mainly loss of the plasma and outer acrosome membranes and acrosome contents (e.g. see Jones, 1971c, Pl. 4, Fig. 19).

\section{EXPLANATION OF PLATE 1}

FIG. 1. Ram spermatozoa fixed in glutaraldehyde in $100 \mathrm{~mm}$-sodium cacodylate, showing the swelling and breakage (arrows) of the plasma membranes around the head. $\times 6750$.

FIG. 2. Ram spermatozoa fixed in glutaraldehyde in $150 \mathrm{~mm}$-sodium cacodylate. Some plasma membranes are swollen and sometimes broken (arrows) whilst others are in close apposition to the acrosome. $\times 6750$.

lig. 3. Bull spermatozoa fixed in glutaraldehyde in $100 \mathrm{~mm}$-sodium cacodylate, showing swelling of the plasma membrane around the head. Note that the swelling is at least as great as for the ram (cf. Fig. 1) but there is no breakage of the membranes. $\times 67,50$.

Fic. 4. Bull spermatozoa fixed in glutaraldehyde in $150 \mathrm{~mm}$-sodium cacodylate, showing that the plasma membrane is in such close apposition to the subjacent outer acrosome membrane that the two are not easily resolved at low magnification. $\times 6750$. The insert demonstrates that the presence of the plasma membrane (m) over the acrosome (a) may be resolved at higher magnifications. $\times 78,000$. 
PLATE 1
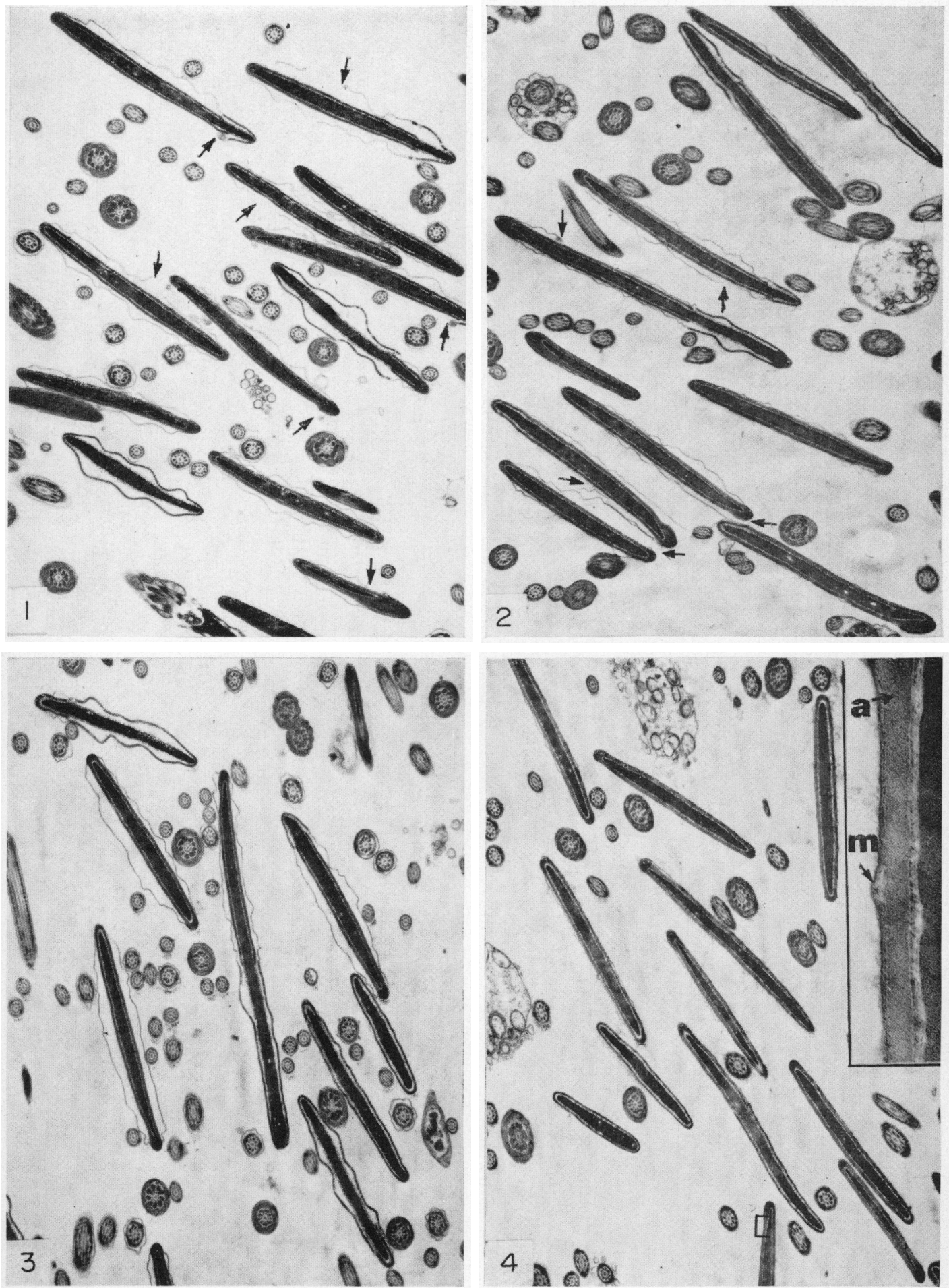
and bull to that described for the boar (Jones, 1971b). The plasma membranes were in close apposition to the subjacent structures in spermatozoa fixed in 175 mM-sodium cacodylate. Fixatives containing lower buffer concentrations caused the membrane to swell and separate from the subjacent structures. The swelling was greatest over the acrosome (Pl. 1, Figs 1 to 4 ) and just detectable around the sperm tails; the amount of swelling was inversely related to the buffer concentration in the fixative (Pl. 1, compare Figs 1 and 3 with Figs 2 and 4).

Considering the average effect on all ejaculates from one species, the plasma membrane over the acrosome of ram spermatozoa fixed in $150 \mathrm{~mm}$-buffer solution showed more swelling (Pl. 1, Fig. 2) than samples from the boar (Jones, 1971 b) and bull (PI. 1, Fig. 4). However, comparisons of electron micrographs of samples prepared in the fixative containing $100 \mathrm{~mm}$-sodium cacodylate showed that the maximum amount of swelling of the plasma membranes of ram, boar or bull spermatozoa was about the same.

Table 2. Summaries of analyses of variance of the estimates of percentages of unbroken plasma membranes shown on Table 1

\begin{tabular}{|c|c|c|c|c|}
\hline \multirow{2}{*}{ Source of variation } & \multirow{2}{*}{$\begin{array}{l}\text { Degrees } \\
\text { of } \\
\text { freedom }\end{array}$} & \multicolumn{3}{|c|}{ Variance ratios } \\
\hline & & Ram & Boar & Bull \\
\hline $\begin{array}{l}\text { Cacodylate concentration } \\
\text { Linear } \\
\text { Quadratic } \\
\text { Remainder }\end{array}$ & $\begin{array}{l}1 \\
1 \\
1\end{array}$ & $\begin{array}{l}29.76^{* * *} \\
10 \cdot 71^{* *} \\
0.00\end{array}$ & $\begin{array}{c}59.48 * * * \\
0.37 \\
0.98\end{array}$ & $\begin{array}{l}4 \cdot 71 \\
0 \cdot 65 \\
1 \cdot 18\end{array}$ \\
\hline $\begin{array}{l}\text { Ejaculates } \\
\text { Residual (error) }\end{array}$ & $\begin{array}{l}3 \\
9\end{array}$ & $\begin{array}{r}6 \cdot 11^{*} \\
25 \cdot 42 \dagger\end{array}$ & $\begin{array}{c}1 \cdot 73 \\
24 \cdot 58 \dagger\end{array}$ & $\begin{array}{l}9 \cdot 78^{* *} \\
9 \cdot 56 \dagger\end{array}$ \\
\hline Theoretical error variance & $\infty$ & $9 \cdot 36$ & 9.95 & $8 \cdot 57$ \\
\hline
\end{tabular}

$* P<0.05 ; * * P<0.01 ; * * * P<0.001$.

$\dagger$ Variance used in $F$-test.

The results of the three $4 \times 4$ randomized block experiments are shown in Tables 1 and 2. The incidence of membrane breakage of ram spermatozoa was high (Pl. 1, Fig. 1) and reached a maximum with the use of about $125 \mathrm{~mm}$ sodium cacodylate; for boar spermatozoa, the incidence of breakage was inversely related to buffer concentration throughout the range used; there was very little breakage of the membranes of bull spermatozoa even in samples fixed in the lowest buffer concentration (PI. 1, Fig. 3). Almost all of the spermatozoa scored as possessing a vacuolated, or more severely damaged, acrosome (Table 1) had lost most of the acrosomal contents. As the plasma membrane of almost all of these spermatozoa must have been broken before fixation, they would not respond to the treatments used. Though the incidence of spermatozoa of this type was slightly higher for boar than for ram or bull samples, a comparison of samples fixed in solutions containing $150 \mathrm{~mm}$-sodium cacodylate showed that the incidence of intact plasma membranes was lowest for the ram, higher for the boar and highest for the bull. This ranking was confirmed with the ejaculates (also prepared using the $150 \mathrm{~mm}$-buffer) from other animals in which the mean percentages $( \pm$ S.E. $)$ of spermatozoa with intact plasma mem- 
branes were: $70 \cdot 2 \pm 4 \cdot 0$ for ejaculates from six rams, $84 \cdot 8 \pm 3 \cdot 4$ for ejaculates from five boars and $92 \cdot 8 \pm 1 \cdot 7$ for ejaculates from five bulls. If these means are pooled with the corresponding means shown in Table 1, they are statistically different from one another.

In separate studies, ram semen was fixed in phosphate-buffered glutaraldehyde and about the same amount of swelling and breakage was observed as in the study using the cacodylate buffer. Jones (1973) showed that there was little effect of varying the glutaraldehyde concentration from 1 to $4 \%$ in a fixative containing $150 \mathrm{~mm}$-sodium cacodylate. Consequently, it is proposed that the plasma membrane breakage observed in these studies was due to the attempt to achieve osmotic equilibrium by water entering the cells, with subsequent swelling and rupture of the membranes (i.e. osmotic shock). Drevius (1972b) found that only $2 \mathrm{sec}$ were required for this process which would be much faster than the penetration and fixation of spermatozoa by molecules of the size and polarity of glutaraldehyde.

As these studies examined differences in response to osmotic shock of the plasma membrane of spermatozoa stressed by dilution and fixation, they are not directly comparable to other studies which have not used such stressful conditions and which have mainly considered just the sperm tail (Dott \& Walton, 1960; Drevius \& Eriksson, 1966; Quinn \& White, 1969; Drevius, 1972a). In the present studies, the plasma membrane covering the sperm head was most sensitive to sudden osmotic stress and swelling in this region would not have been observed in the other studies mentioned above. Furthermore, although these studies provide additional evidence to support the thesis (Drevius, 1972b) that bull spermatozoa behave as osmometers, they also indicate that ram and boar spermatozoa may not behave as osmometers except over a very limited range of diluent osmolalities in which their membranes would remain intact. The observed differences in sensitivity to membrane breakage of spermatozoa from different species may explain the disagreement between several workers concerning the swelling of ram (Quinn \& White, 1969) and bull (Drevius \& Eriksson, 1966) spermatozoa in hypotonic solutions.

The conclusion that the plasma membranes of bull spermatozoa are less sensitive to breakage than those of ram or boar spermatozoa provides a reason why bull spermatozoa are the least susceptible to damage from handling in the laboratory or preparation for artificial insemination (Jones, 1971a; Mann, 1964). Observations of published electron micrographs of rabbit spermatozoa (Bedford, 1964, 1965; Hadek, 1963a, b) suggest that they would also behave like bull spermatozoa. This would also explain why they are relatively insensitive to physical stress (Jones, 1971a). It is suggested that the methods of fixing and examining spermatozoa by electron microscopy used in these studies may provide a useful measure of predicting the ease with which spermatozoa from different species may be stored for artificial insemination.

I am grateful to Mrs P. A. Gallant and Mr T. J. Dennett for technical assistance. The work was supported by grants from the Wellcome Trust, the Meat and Livestock Commission and Unilever Ltd. The author was supported by a Ford Foundation Fellowship. 


\section{REFERENCES}

Bedroro, J. M. (1964) Fine structure of the sperm head in ejaculate and uterine spermatozoa of the rabbit. F. Reprod. Fert. 7, 221.

BeDford, J. M. (1965) Changes in fine structure of the rabbit sperm head during passage through the epididymis. 7. Anat. 99, 891.

Dotт, H. M. \& WaLton, A. (1960) Effects of dilution and washing on ram spermatozoa studied by the flow dialysis technique. 7. Reprod. Fert. 1, 350.

Drevius, L.-O. (1972a) Water content, specific gravity and concentrations of electrolytes in bull spermatozoa. F. Reprod. Fert. 28, 15.

Drevius, L.-O. (1972b) Bull spermatozoa as osmometers. F. Reprod. Fert. 28, 29.

Drevius, L.-O. \& ERIKsson, H. (1966) Osmotic swelling of mammalian spermatozoa. Expl Cell Res. 42, 136.

HADEK, R. (1963a) Submicroscopic changes in the penetrating spermatozoon of the rabbit. F. Ultrastruct. Res. 8, 161.

Hadek, R. (1963b) Study on the fine structure of rabbit sperm head. 7. Ultrastruct. Res. 9, 110.

JoNEs, R. C. (197l a) Uses of artificial insemination. Nature, Lond. 229, 534.

JoNEs, R. C. (197lb) Ultrastructure of mammalian spermatozoa: the effects of buffer concentration in fixatives for boar spermatozoa. Micron, 2, 350 .

Jones, R. C. (1971c) Studies of the structure of the head of boar spermatozoa from the epididymis. $\mathcal{F}$. Reprod. Fert. Suppl. 13, 51.

Jones, R. G. (1973) Preparation of spermatozoa for electron and light microscopy. F. Reprod. Fert. 33, 145.

ManN, T. (1964) The biochemistry of semen and of the male reproductive tract. Methuen, London.

Nichols, G. De La M. \& Edgar, D. G. (1964) A transistorized rectal probe for ejaculating rams. N.Z. vet. F. 12, 145.

Quinn, P. J. \& White, I. G. (1969) Osmotic shock of ram spermatozoa. F. Reprod. Fert. 18, 375. 